\title{
Transport of intravenously-injected ferritin across the guinea-pig synovium
}

\author{
M. A. ChAMBERlain, V. PETtS, AND E. GOLlinS \\ From the Departments of Rheumatology and Immunology, The Middlesex Hospital, London
}

Immune complexes have been found in the synovial fluid (Rawson, Abelson, and Hollander, 1965) and synovium (Kinsella, Baum, and Ziff, 1970) of patients with rheumatoid arthritis. They have also been discovered in the blood in cases of the same disease (Kunkel, Müller-Eberhard, Fudenberg, and Tomasi, 1961) and their presence has lead to speculation on their role in the aetiology of rheumatoid disease. It is known that in conditions such as HenochSchönlein purpura, in which circulating immune complexes are abundant, arthritis is frequent. If such circulating complexes were responsible for inflammatory arthritis, or if complexes in the joint were transported to the circulation to produce remote pathological changes, it would be of interest to know the route they follow, and the time taken for the transport of such large protein particles. This primary study aims to show that such a pathway for proteinmaterial exists. A large, electron dense tracer, ferritin, was injected intravenously into guinea-pigs and its passage from the synovial blood vessel lumen to the synovial cells observed over the course of 8 days.

The cellular ultrastructure of normal synovium has been well documented, but the rich vasculature of the synovium has received much less attention, even though the rapid interchange of soluble particles across the vascular endothelium has been demonstrated (Rodnan and MacLachlan, 1960) and may be of importance in some disease states. There may be some anatomical peculiarity of the synovial vasculature which induces preferential deposition of immune complexes in the synovium (rather as the kidney is frequently involved in systemic lupus erythematosus). The morphology of guinea-pig synovial vascular endothelium was therefore studied and compared with that in other sites.

\section{Material and methods}

Male guinea-pigs weighing 200-700 g. were used for all experiments. Each animal was lightly anaesthetized with either nembutal $(0 \cdot 6 \mathrm{ml} . / 100 \mathrm{~g}$. body weight) or with ether Ferritin (equine spleen, cadmium free, $B$ grade, mantfactured by Pentex Laboratories, $100 \mathrm{mg}$. $/ \mathrm{ml}$.) was injected slowly into a penile vein. In earlier experiments, the intracardiac route was used but as some animals died with the dose of ferritin used $(1 \mathrm{ml} . / 100 \mathrm{~g}$.) this was later abandoned. The dose of ferritin used in the study (1-2 ml.) did not produce any depression in the level of consciousness and allowed the animals to recover quickly.

Guinea-pigs were killed with ether followed by intracardiac nembutal, at $10 \mathrm{~min}$., $30 \mathrm{~min}$., $60 \mathrm{~min}$., $90 \mathrm{~min}$., 24 hrs, 2 days, 5 days, and 8 days. Two animals were examined at each point in the time scale. Glutaraldehyde 3 per cent. was immediately injected intra-articularly into both knees to fix the synovium, which was then dissected off under the dissecting microscope; some was processed for light microscopy and stained with haematoxylin and eosin, Perls's stain, and neutral red. Sections from the liver, kidney, and spleen were stained similarly for light microscopy to confirm the presence of iron in the tissues of the experimental animal at the chosen times.

For electron microscopy, the synovium was diced in cold 3 per cent glutaraldehyde in which it was fixed for 30-60 min. After three washes in phosphate buffer and fixation in 2 per cent osmium tetroxide for 1 hour, tissues were processed and embedded in araldite. Thin sections were examined in AE1 6B electron microscope. The sections were not contrast-stained with lead or uranyl salts as the high density of the tissue tends to obscure the ferritin particles.

\section{Results}

Endothelial cells were $2-3 \mu$ wide at the nucleus, narrowing peripherally. In these peripheral areas cytoplasmic vesicles and pits opening onto the tissue surface were also seen. Attenuated portions of the cell accounted for up to 20 per cent. of the circumference of the capillary; frequently, attenuation occurred on the side of the vessel nearer to the synovial fluid (Fig. 1, overleaf) but this orientation was not invariable.

Fenestrae, as described by Schumacher (1969), were rarely seen. Dense junctions were often seen along contiguous endothelial surfaces. 
Thin sections of guinea-pig synovium examined in an AEI 6 B electron microscope. The sections were fixed in osmium tetroxide and embedded in araldite. They were not contrast stained as the high density of the tissue tends to obscure the ferritin particles

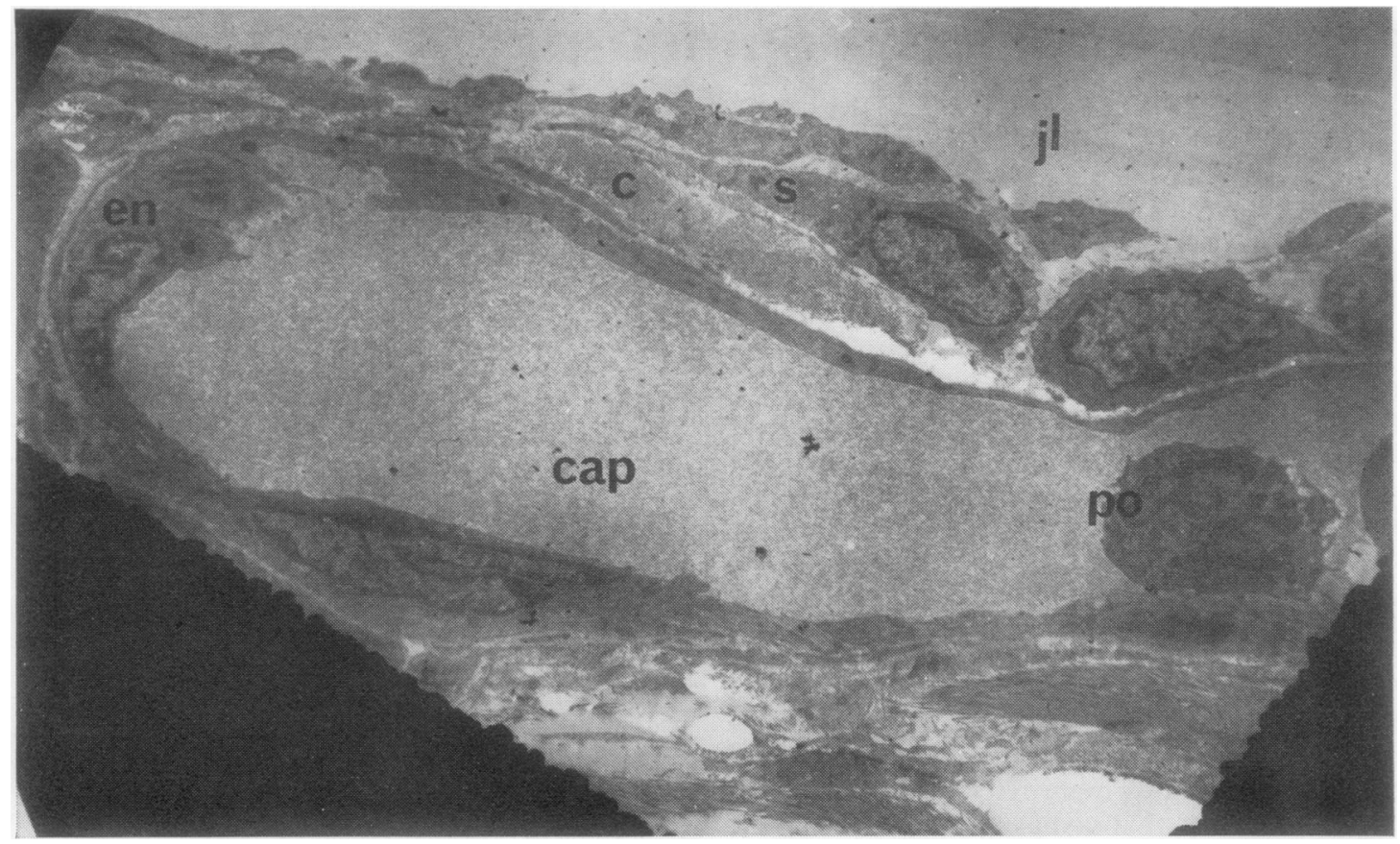

FIG. 1 Section to show proximity of synovial capillary (cap) to joint lumen $(j l)$. The lumen is separated from the joint lumen by a single layer of attenuated vascular endothelium (en), collagen fibres $(c)$, and two synovial cells $(s)$. The vessel contains a polymorphonuclear cell $(p o) . \times 3,000$

Pericytes and the basement membrane around synovial vessels resembled those surrounding other vessels, but the latter was seen only in stained sections. The adventitia consisted of a loose matrix containing collagen in which were found fibroblasts and occasional macrophages. These small vessels often lay immediately underneath the synovial cells or their extensions: a very short distance thus separated substances in the lumen of the vessel from the joint space.

Synovial cells lined the joint either continuously (as in areolar synovium where the synovium was several cells thick) or discontinuously and thinly (as in fibrous synovium). As has been stated in many descriptions of synovial ultrastructure (Ghadially and Roy, 1969), two basic cells types are found, A cells which are vacuolar, similar to macrophages, and probably phagocytic, and $\mathbf{B}$ cells containing abundant endoplasmic reticulum. Intermediate types also exist.

\section{LOCALIZATION OF FERRITIN}

Lumen Ferritin was observed in the vessel lumina at $10 \mathrm{~min}$. and large quantities, evenly distributed, were seen at $1 \mathrm{hr}$ (Fig. 2). Moderate amounts of the tracer were still present at 2 days but had disappeared by 8 days.
Endothelial cells Ferritin was never seen free in the cytoplasm of vascular endothelium although it was present in clear vesicles in the cytoplasm in sections taken at $10 \mathrm{~min}$. and $1 \mathrm{hr}$ (Fig. 2). At these times it was also seen in pits opening onto the blood vessel lumen as well as in basal pits (on the basement membrane side of the endothelial cell) (Fig. 2, opposite.

As mentioned above, very few fenestrae were seen; only occasional particles of ferritin lay in their vicinity; and no tracer molecules were found within the fenestrae.

There was no ferritin in dense junctions, or along any endothelial cell junctions.

Endoplasmic pseudopodia partially enclosing ferritin particles were very rare.

Basement membrane No accumulations of ferritin were found within the basal lamina or at its endothelial face. A light scatter of particles occurred throughout its thickness (Fig. 3, overleaf) in sections taken at $1 \mathrm{hr}$.

Pericytes Ferritin was occasionally present in significant amounts free in the cytoplasm, mainly at $1 \mathrm{hr}$ (Fig. 2).

Adventitia Occasionally fibroblasts containing ferritin were observed. Numerous degranulated eosinophils were present at 5 days. 


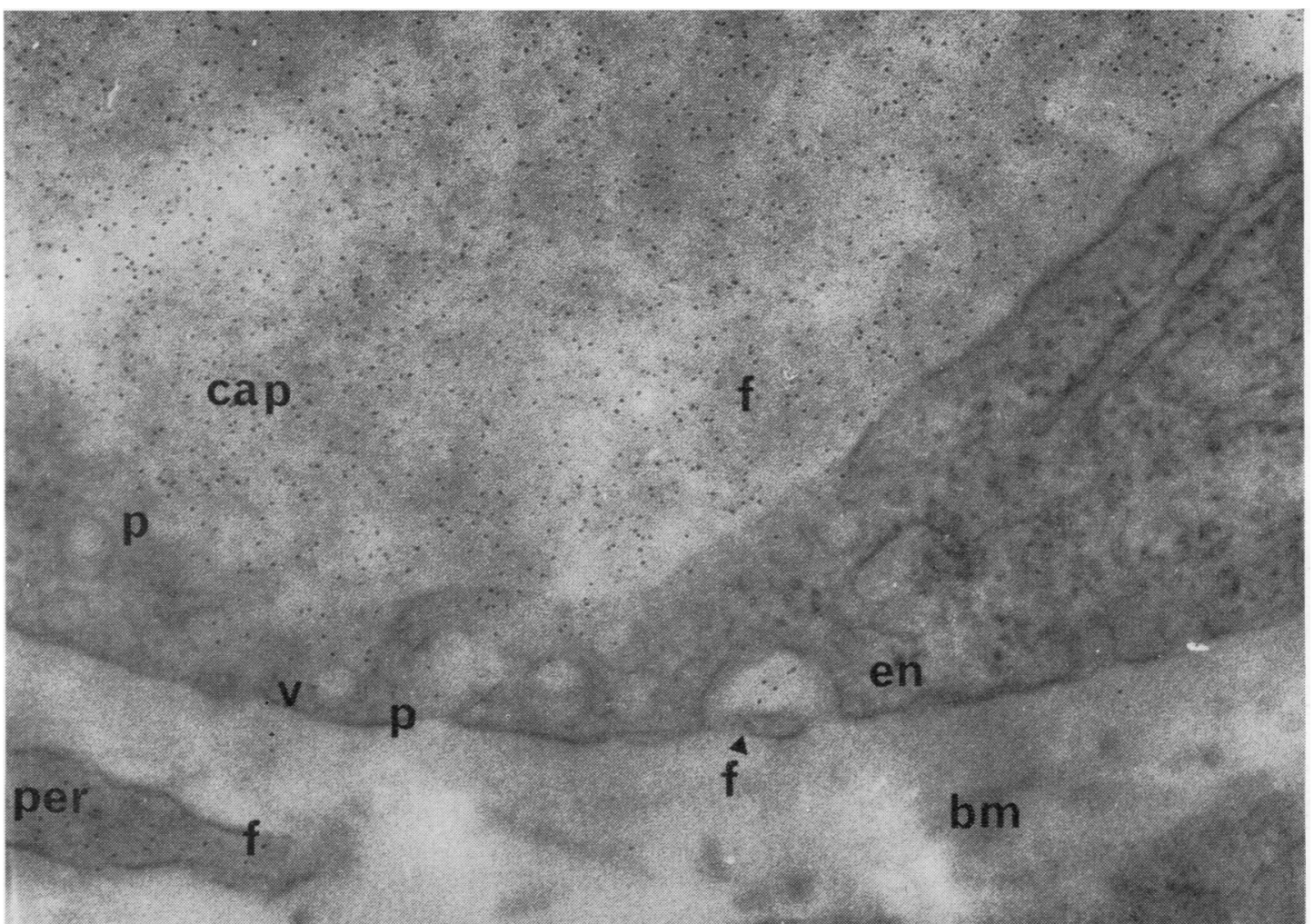

FIG. 2 Section taken $1 \mathrm{hr}$ after the intravenous injection of ferritin $(f)$. Much ferritin is present in the capillary lumen (cap) and is separated from the basement membrane ( $(\mathrm{bm})$ by attenuated cytoplasm of a vascular endothelial cell (en). Pits ( $p$ ) open onto the luminal and basal sides of the cell. Several pits on both fronts contain ferritin particles (arrow). Ferritin is also present in vesicles $(v)$ of the endothelial cell. It is not found free in the cytoplasm. Free ferritin $(f)$ is found in the cytoplasm of a pericyte (per). $\times 60,000$

Synovial cells 1 hour after intravenous administration of ferritin, the tracer was present in large quantities, fairly evenly distributed throughout type A synovial cells. It was present in synovium at all times after this, and was also found in a macrophage-type synovial cell lying loose on the joint lumen at $10 \mathrm{~min}$. No Type B cells took up ferritin though it was occasionally seen in intermediate cells.

Some cytoplasmic aggregation of ferritin had begun by $1 \mathrm{hr}$ and ferritin had also become membranebound in various types of vesicles, some with clear contents, some containing dense material in addition to tracer. Many vesicles remained free of tracer. From 24 hrs to 8 days, only minor changes occurred in synovial cells. Much ferritin remained free in the cytoplasm but more gradually became incorporated into large vacuoles (Figs 4 and 5, overleaf). Ferritin was never seen in the extracellular space or free in the joint lumen.

\section{LIGHT MICROSCOPY}

This confirmed the above findings.

In early specimens much ferritin had passed into the liver and spleen, so that these tissues gave a strongly positive reaction for iron by Perls's method. At this time, although ferritin was seen to be present in the synovium and its vessels when these were examined with the electron microscopy, there was insufficient ferritin in the synovium to stain positively for iron up to $1 \frac{1}{2} \mathrm{hrs}$ after injection of the tracer.

\section{Discussion}

Majno (1965) has discussed the basic types of capillary endothelium and divided them into three:

TYPE 1 Continuous capillary with a continuous epithelial sheet as found in striated muscle, lung, placenta, and subcutaneous and adipose tissues.

TYPE 2 Fenestrated capillaries with intracellular openings.

TYPE 3 Discontinuous capillaries, as found in the liver, bone marrow, and spleen.

The second type of endothelium is found at sites where absorption or production of fluids occurs (e.g. the renal glomerulus, choroid plexus, intestinal villus) and has been reported by Majno (1965) to be present in rat synovium. Schumacher (1969) noted 
FIG. 3 Section taken at $1 \mathrm{hr}$. Ferritin is evenly distributed in the capillary lumen (cap). It has also crossed the attenuated vascular endothelium (en) and small amounts are seen in the basement membrane (bm). $\times 90,000$

the occurrence of fenestrae in the superficial capillaries of the synovium of the Cebus albifrons monkey though deeper vessels had thicker endothelial cells. It was expected therefore that numerous fenestrae would also be found in guinea-pig synovium but, in fact, most endothelium seen in this study was of Majno's first type and substantial areas were greatly attenuated. This difference might be related to species, or was perhaps due to the different areas of synovium studied. Majno chose fat-pad synovium; in this study areolar synovium adjacent to the patella was regularly taken.

Several pathways for the transport of iron particles are theoretically possible: transport directly across the endothelial cytoplasm, or through fenestrae, or between cells is the most obvious. Free tracer has been noted to be absent from the endothelial cytoplasm of other tissues (Farquhar, Wissig, and Palade, 1961). No studies have shown more than occasional particles in cytoplasmic junctions. Although numerous fenestrae have been reported in areas where much interchange of material takes place (Rhodin (1962) calculated that in renal medulla fenestrae occupy 35 per cent. available area), there is no electron microscopic evidence for this mode of transport (Majno, 1965). The present investigation yields similar findings in the synovium: ferritin was absent from the cytoplasm of vascular endothelium, cell junctions, and the few fenestrae that were seen.

Bruns and Palade (1968) showed that, in striated

FIG. 42 days after the intravenous administration of ferritin. Detail of a synovial cell containing numerous vacuoles (vac) and little endoplasmic reticulum (er). Ferritin is free in the cytoplasm and also present in both densely staining and clearer vacuoles. $\times 60,000$

FIG. 58 days after intravenous administration of ferritin. Detail of a synovial cell ( $A$ type) containing vacuoles (vac) more heavily laden with ferritin $(f)$. Ferritin also remains throughout the cytoplasm in individual particles and aggregations. $\times$ 67,000 

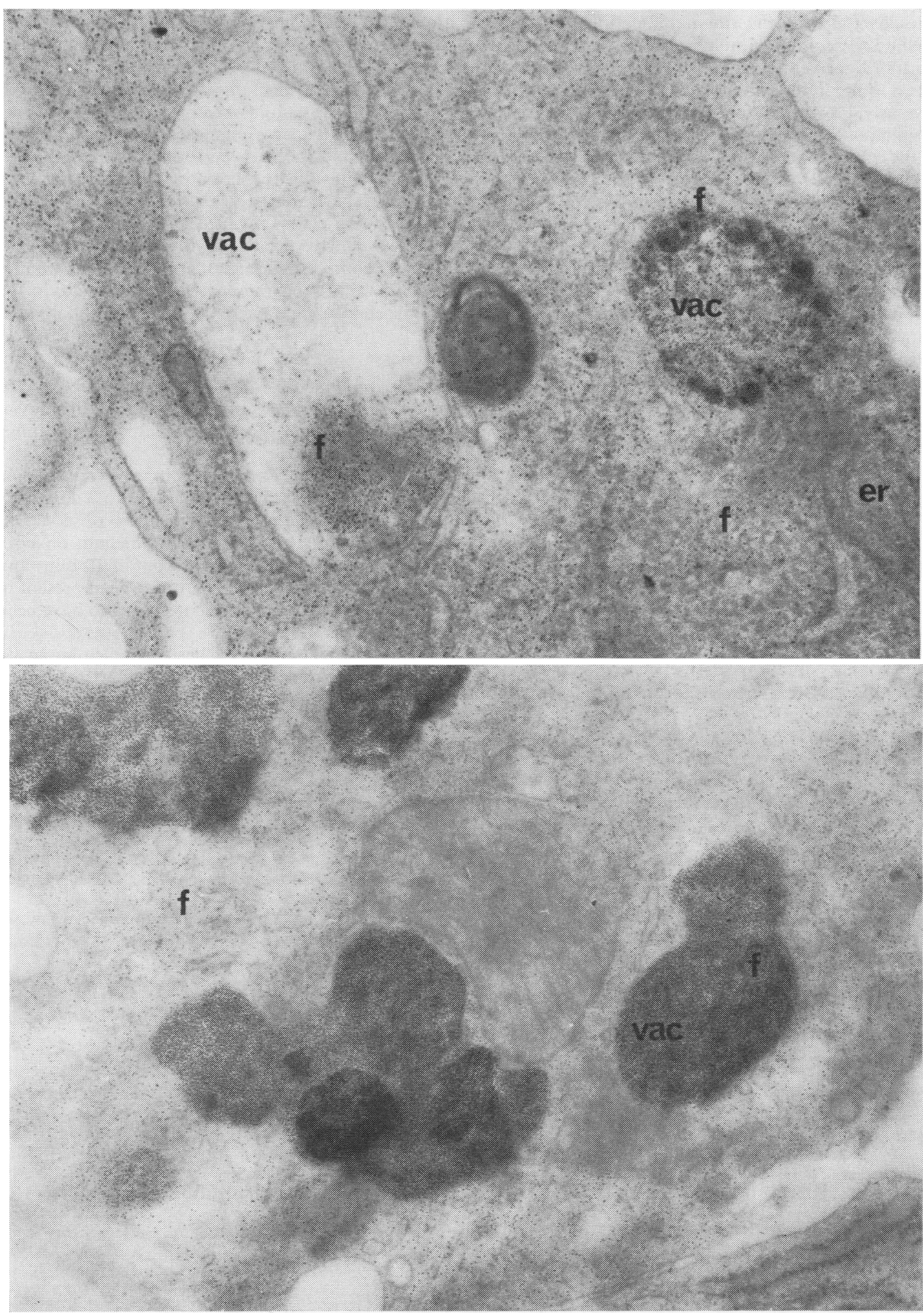
muscle capillaries, the attenuated periphery of endothelial cells contained numerous vesicles comprising up to 18 per cent. of the cell volume at this point. They found that, when ferritin was injected intravenously, it was soon found in chains of these vesicles opening onto both the luminal and the basal surfaces of the cell. Similar chains of small vesicles were found in the synovial vessels examined in the present study and look remarkably like a ferrying system. If this is so, it seems to be a more important mechanism than any passive transport across fenestrae.

The endothelial cells themselves presented the main barrier to particle transport. A large concentration gradient existed initially between the vessel lumen and the synovial cell. Very little ferritin was seen in positions intermediate between the endothelium and the synovium, probably indicating rapid transport between these two sites. Furthermore, ferritin did not collect at the basement membrane, indicating that the membrane was not a significant barrier. This is in contrast to other tissues-for example, the renal glomerulus-in which the basal lamina is the main barrier (Farquhar and Palade, 1962).

Ferritin was found consistently in macrophage-like synovial cells (A type), occasionally in intermediate types, but never in B cells.

Light microscope studies (Consden, Doble, Glynn, and Nind, 1971; Chamberlain, unpublished) indicate that a similar situation exists when carbon is injected intra-articularly. It persists deep in the synovium for at least 6 weeks.

Entry into the synovial cell may also occur by pinocytosis. However, numerous particles of ferritin were seen free in the cytoplasm as well as within vacuoles larger than those seen in endothelial cells. In the early stage (up to $24 \mathrm{hrs)}$ the majority was free in the cytoplasm but later ( 5 to 8 days) more ferritin became membrane-bound in vacuoles, which varied in their morphology and electron density. Some vacuoles remained free of ferritin. Similar ultrastructural localization of iron particles was reported after intra-articular injections (Ball, Chapman, and Muirden, 1964) and in long-standing rheumatoid arthritis (Muirden, 1966); Consden and others (1971) have shown that, in the immunized animal, antigen (in this case ovalbumin) persists in the synovium in minute but active amounts for up to 4 or 5 months when immunization is performed with Freund's complete adjuvant. It therefore seems that there are occasions, particularly when the synovium is inflamed, when the synovial cells clear large foreign particles slowly, whatever their route of entry. Immune complexes are probably handled similarly to ferritin and their presence may contribute to the chronic changes characteristic of rheumatoid disease.

\section{Summary}

(1) Ferritin was administered intravenously to guinea-pigs and its passage from the small synovial blood vessel lumen was observed for from $10 \mathrm{mins}$ to 8 days.

(2) High concentrations of ferritin were found in the blood vessel lumina for from 10 mins to 2 days.

(3) Ferritin particles were frequently observed in invaginations of the vascular endothelium on both the luminal side and the tissue front at 10 mins and $1 \mathrm{hr}$, when vesicles containing tracer were present in these cells. Ferritin was thus considered to have been 'ferried' across these cells.

(4) The vascular endothelial basement membrane did not present a barrier to the passage of ferritin.

(5) Ferritin was quickly taken up by synovial Type A cells, a small amount being present at 1 hour. By 2 to 8 days large concentrations of this tracer were found free in the cytoplasm of these cells and accumulating in many types of vacuoles. Ferritin was not found in Type B cells.

We are happy to acknowledge the generous help given to us by Prof. I. M. Roitt, Dr. Marion Hicks, Mr. K. Nandal, and Dr. K. Henry.

One of us (M.A.C.) was also partially financed by the Arthritis and Rheumatism Council.

\section{References}

Ball, J., Chapman, J. A., ANd Muirden, K. D. (1964) J. Cell Biol., 22, 351 (The uptake of iron in rabbit synovial tissue following intra-articular injection of iron-dextran)

BRuns, R. R., AND Palade, G. E. (1968) Ibid., 37, 277 (Studies on blood capillaries II Transport of ferritin molecules across the wall of muscle capillaries)

Consden, R., Doble, A., Glynn, L. E., AND Nind, A. P. (1971) Ann. rheum. Dis., 30, 307 (Production of a chronic arthritis with ovalbumin. Its retention in the rabbit knee joint)

FARQUHAR, M. G., AND PALADE, G. E. (1962) 'Incorporation of electron-opaque tracers by cells of the renal glomerulus', in 'Electron Microscopy: Fifth International Congress, Philadelphia, 1962', ed. S. S. Breese, Jr., vol. 2, p. LL-3. Academic Press, New York

- Wissig, S. L., AND PALADE, G. E. (1961) J. exp. Med., 113, 47 (Glomerular permeability. I. Ferritin transfer across the normal glomerular capillary wall)

GHADIALly, F. N., AND RoY, S. (1969) 'Ultrastructure of Synovial Joints in Health and Disease'. Butterworths, London

Kinsella, T. D., Baum, J., AND ZifF, M. (1970) Arthr. and Rheum., 13, 734 (Studies of isolated synovial lining cells of rheumatoid and non-rheumatoid synovial membranes) 
Kunkel, H. G., Müller-Eberhard, H. J., Fudenberg, H. H., AND Tomasi, T. B. (1961) J. clin. Invest. 40, 117 (Gamma globulin complexes in rheumatoid arthritis and certain other conditions)

MajNo, G. (1956) 'Ultrastructure of the vascular membrane', in 'Handbook of Physiology', Section 2, Circulation, ed. W. F. Hamilton, vol. 3, chap. 64, p. 2293. American Physiological Society, Washington, D.C.

MuIRDEN, K. D. (1966) Ann. rheum. Dis. 25, 387 (Ferritin in synovial cells in patients with rheumatoid arthritis)

Rawson, A. J., Abelson, N. M., And Hollander, J. L. (1965) Ann. intern. Med., 62, 281 (Studies on the pathogenesis of rheumatoid joint inflammation. II. Intracytoplasmic particulate complexes in rheumatoid synovial fluids)

RhodIN, J. A. (1962) J. Ultrastruct. Res., 6, 171 (The diaphragm of capillary endothelial fenestrations)

Rodnan, G. P., AND MacLachlan, M. J. (1960) Arthr. and Rheum., 3, 152 (The absorption of serum albumin and gamma globulin from the knee joint of man and rabbit)

SCHUMACHeR, H. R. (1969) Ibid., 12387 (The micro-vasculature of the synovial membrane of the monkey: ultrastructural studies) 